\title{
Article \\ Effect of Ignition Energy and Hydrogen Addition on Laminar Flame Speed, Ignition Delay Time, and Flame Rising Time of Lean Methane/Air Mixtures
}

\author{
Minh Tien Nguyen ${ }^{1, *}{ }^{\oplus}$, Van Van Luong ${ }^{2}$, Quoc Thai Pham ${ }^{3}{ }^{-}$, Minh Tung Phung ${ }^{1}$ and Phu Nguu Do ${ }^{1}$ \\ 1 Department of Mechanical Engineering, The University of Danang-University of Technology and Education, \\ Da Nang 50000, Vietnam; pmtung@ute.udn.vn (M.T.P.); dpnguu@ute.udn.vn (P.N.D.) \\ 2 Faculty of Automotive Engineering Technology, Vinh Long University of Technology Education, \\ Vinh Long 85000, Vietnam; vanlv@vlute.edu.vn \\ 3 Faculty of Transportation, The University of Danang-University of Science and Technology, \\ Da Nang 50000, Vietnam; pqthai@dut.udn.vn \\ * Correspondence: nmtien@ute.udn.vn
}

check for

updates

Citation: Nguyen, M.T.; Luong, V.V.; Pham, Q.T.; Phung, M.T.; Do, P.N. Effect of Ignition Energy and Hydrogen Addition on Laminar Flame Speed, Ignition Delay Time, and Flame Rising Time of Lean Methane/Air Mixtures. Energies 2022, 15, 1940. https://doi.org/10.3390/ en15051940

Academic Editor: Pavel A. Strizhak

Received: 4 February 2022

Accepted: 2 March 2022

Published: 7 March 2022

Publisher's Note: MDPI stays neutral with regard to jurisdictional claims in published maps and institutional affiliations.

Copyright: (C) 2022 by the authors. Licensee MDPI, Basel, Switzerland. This article is an open access article distributed under the terms and conditions of the Creative Commons Attribution (CC BY) license (https:/ / creativecommons.org/licenses/by/ $4.0 /)$.

\begin{abstract}
A series of experiments were performed to investigate the effect of ignition energy $\left(\mathrm{E}_{\mathrm{ig}}\right)$ and hydrogen addition on the laminar burning velocity $\left(S_{u}{ }^{0}\right)$, ignition delay time $\left(t_{\text {delay }}\right)$, and flame rising time $\left(t_{\text {rising }}\right)$ of lean methane-air mixtures. The mixtures at three different equivalence ratios $(\phi)$ of $0.6,0.7$, and 0.8 with varying hydrogen volume fractions from 0 to $50 \%$ were centrally ignited in a constant volume combustion chamber by a pair of pin-to-pin electrodes at a spark gap of $2.0 \mathrm{~mm}$. In situ ignition energy ( $\mathrm{E}_{\mathrm{ig}} \sim 2.4 \mathrm{~mJ} \div 58 \mathrm{~mJ}$ ) was calculated by integration of the product of current and voltage between positive and negative electrodes. The result revealed that the $S_{u}{ }^{0}$ value increases non-linearly with increasing hydrogen fraction at three equivalence ratios of $0.6,0.7$, and 0.8 , by which the increasing slope of $S_{u}{ }^{0}$ changes from gradual to drastic when the hydrogen fraction is greater than $20 \% . t_{\text {delay }}$ and $t_{\text {rising }}$ decrease quickly with increasing hydrogen fraction; however, $t_{\text {rising }}$ drops faster than $t_{\text {delay }}$ at $\phi=0.6$ and 0.7 , and the reverse is true at $\phi=0.8$. Furthermore, $t_{\text {delay }}$ transition is observed when $\mathrm{E}_{\mathrm{ig}}>\mathrm{E}_{\mathrm{ig} \text {,critical }}$, by which $t_{\text {delay }}$ drastically drops in the pre-transition and gradually decreases in the post-transition. These results may be relevant to spark ignition engines operated under lean-burn conditions.
\end{abstract}

Keywords: ignition energy; hydrogen; lean methane/air mixture; laminar flame speed; ignition delay time; flame rising time

\section{Introduction}

The use of alternative fuels, together with lean combustion technology, is an effective way of reducing emissions and enhancing the thermal efficiency of internal combustion engines (ICE) [1-6]. Natural gas (mostly methane) and hydrogen are considered the alternative fuels for ICEs. Natural gas combustion emits lower greenhouse gas emissions than gasoline because of its high $\mathrm{H} / \mathrm{C}$ ratio. The high knock resistance of natural gas potentially allows the ICEs to operate under higher compression ratios. Burning the lean natural gas/air mixtures is a promising method for enhancing the thermal efficiency of spark ignition (SI) engines through an increase in the specific heat ratio [7] and the reduction in heat-transfer losses due to its lower combustion temperature together with a decrease in the pumping loss for the wide-opening throttle [5,8]. However, methane has a slower flame propagation that may cause misfire [8-10], high cycle-to-cycle variation, and emission of unburned hydrocarbon [1,11]. The slower development of flame kernel and thus the longer explosion duration interfere with an optimal combustion phasing [10] in SI engines, limiting the full potential of lean combustion. How to accelerate the flame kernel propagation and the explosion duration of lean natural gas is thus crucial to the further development of high thermal efficiency and low-emission SI engines. 
Owing to the large burning velocity and lower flammability limit, hydrogen is a candidate fuel for stabilizing lean operations and reducing emissions of natural gas engines [12-15]. For instance, Ma et al. [12] reported that the excess air ratio of purely natural gas at $105 \mathrm{kPa}$ of manifold absolute pressure was 1.71 and could be extended to 1.82, 2.09, and 2.4 by adding $10 \%, 30 \%$, and $50 \%$ in volume fraction of $\mathrm{H}_{2}$, respectively. By substituting less than $50 \%$ volume fraction of hydrogen to methane, Akansu et al. [15] revealed the reduction in $\mathrm{CO} / \mathrm{CO}_{2}$ emissions and improvement of the brake thermal efficiency at lean conditions. Karim et al. [14] suggested that a small amount of hydrogen in methane would not undermine the knock resistance ability of methane.

Fundamental studies on hydrogen-methane flames have shown that laminar burning velocity increases with an increase in hydrogen mole fraction in the fuel [1,14,16-20]. Studying the spherical propagation of hydrogen-methane flames at three equivalence ratios $(\phi)$ of $0.8,1.0$, and 1.2 in the constant volume combustion chamber (CVCC), Okafor et al. [1] showed that the un-stretched laminar burning velocities increase non-linearly with increasing hydrogen faction. Chen et al. [17] found a similar result by using a computational method. Hu et al. [19] experimentally and numerically studied hydrogen-methane flames over a wide range of equivalence ratios $(\phi=0.6 \sim 1.4)$ and hydrogen additions $(0 \sim 100 \%$ in volume fraction). They reported that the un-stretched laminar burning velocity increases, and its peak value shifts to the richer mixture side with increasing hydrogen fraction due to the increase in $\mathrm{H}, \mathrm{O}$, and $\mathrm{OH}$ radical mole fraction in the flame. The increasing burning rate of hydrogen-methane flames could be also attributed to the effect of hydrogen on the flow field. This is achieved by increasing the velocity of the main toroidal vortex and generating the different sub-vortices within the main vortex [21]. However, the results found by $\mathrm{Hu}$ et al. [19] are generally $5 \mathrm{~cm} / \mathrm{s}$ faster than those of Donohoe et al. [20]. The uncertainty of valuable data in the literature and the lack of data on such lean hydrogen-methane flames (i.e., $\phi=0.6 \sim 0.8$ ) suggests that more studies on lean hydrogen-methane flames are still necessary for the development and validation of combustion models as well as the optimization of gas engines designs.

Explosion duration characteristics and the rise of in-chamber explosion pressure are essential to the optimization design in hydrogen-methane applications. An optimum explosion duration is essential to avoid pre-ignition and obtain optimal combustion phasing in SI engines. Despite numerous studies available in the literature (see Refs. [1,14,16,17,19,20] and the references therein), unfortunately, most of them focus on the laminar burning velocity of hydrogen-methane flames rather than their explosion duration characteristics. Recently, Sun et al. [22] have conducted the stoichiometric syngas with different hydrogen concentrations (10-90\% in volume fraction) in a spherical combustion chamber. They investigated that the increasing hydrogen fraction could raise the maximum pressure and shorten the explosion duration due to the increase in $\mathrm{H}^{+}$in the flame. Salzano et al. [23] showed that the rising slope of the maximum rate of pressure rise changes from gradual to drastic when the hydrogen fraction is greater than $50 \%$ in the stoichiometric hydrogen-methane mixture. Wang et al. [24] investigated combustion behaviors of the natural gas-hydrogen blends in a direct injection engine. The results showed that the rapid combustion duration decreased while the heat release rate and exhaust NOx increased with increased hydrogen fraction. Wang et al. [24] suggested that an optimum hydrogen volume fraction of $20 \%$ should be used to get the compromise in both engine performance and emissions.

To quantify the explosion duration characteristics, many researchers investigated ignition delay time (lag duration) and flame rising time (fast burn duration) [22,25-27]. The ignition delay time $\left(t_{\text {delay }}\right)$ is the time duration between the start of spark command and the instant of appearance of pressure [22,25] or $10 \%$ of the total normalized cumulative heat release $(\mathrm{NCHR})$ [26]. The flame rising time $\left(t_{\text {rising }}\right)$ is defined as the time duration from $10 \%$ to $90 \%$ of the total NCHR [26]. In a practical SI engine, $t_{\text {delay }}$ is introduced as an inflammation time measured from the spark timing to $5 \%$ burn point (CA5), and $t_{\text {rising }}$ is the main combustion duration time obtained from CA10 to CA90 [27]. To lessen $t_{\text {delay }}$ and $t_{\text {rising, }}$ an increase in the ignition energy $\left(\mathrm{E}_{\mathrm{ig}}\right)$ could be useful. Kelley et al. [28] and 
Chen et al. $[29,30]$ reported that increasing $E_{\mathrm{ig}}$ could enhance the early flame propagation speed shortly after the spark discharge, resulting in a shorter explosion duration. This is because the larger $\mathrm{E}_{\mathrm{ig}}$, the higher concentration of active radicals inside the spark gap [31] and/or the higher chemical power release [32]. Moreover, for laminar $\mathrm{CH}_{4} / \mathrm{O}_{2} / \mathrm{N}_{2} / \mathrm{He}$ spherical flames, Zhou et al. [33] found that the increasing $\mathrm{E}_{\mathrm{ig}}$ in a specific range could promote the early flame propagation speed; beyond such range, the additional $\mathrm{E}_{\mathrm{ig}}$ has a marginal effect on the early flame propagation speed, as it does for the explosion duration. To the best of the authors' knowledge, experimental studies on the explosion duration characteristics of such lean hydrogen-methane flames over a wide range of hydrogen fraction and ignition energy are sparse.

In this study, we experimentally investigate the effect of ignition energy $(2.4 \mathrm{~mJ}$ to $58 \mathrm{~mJ}$ ) and hydrogen addition ( 0 to $50 \%$ in volume fraction) on the laminar burning velocity and explosion duration characteristics of lean methane/air mixtures at $\phi=0.6,0.7$, and 0.8 . The mixtures are centrally ignited in the constant volume combustion chamber by a pair of pin-to-pin electrodes having a spark gap $\left(d_{\text {gap }}\right)$ of $2 \mathrm{~mm}$. There are differences from previous studies: (1) the laminar burning velocity is calculated by pressure-rise method; (2) the effect of ignition energy and hydrogen addition on $t_{\text {delay }}$ and $t_{\text {rising }}$ of lean methane/air mixtures is analyzed for the first time.

\section{Methodology}

\subsection{Experimental Setup, Procedure, and Conditions}

Experiments of lean methane/hydrogen/air mixture at equivalence ratios $(\phi)$ of 0.6, 0.7 , and 0.8 were conducted in a constant volume combustion chamber at atmospheric conditions using the car ignition coil, as shown in Figure 1. The volume fraction of hydrogen was varied from 0 to $50 \%$ ( $\mathrm{H} 0$ to $\mathrm{H} 5)$ in the combustible mixtures. The nominal purity of the used gases was more than $99.9 \%$. The stainless-steel vessel with an inner diameter of $160 \mathrm{~mm}$ was equipped with intake and exhaust ports, a pair of pin-to-pin electrodes, and two pressure transducers $\left(\mathrm{P}_{1}\right.$ and $\left.\mathrm{P}_{2}\right)$. A pressure transducer $\mathrm{P}_{1}$ (CSR1 model, $\pm 0.5 \%$ FS) having a range of -1 to 3 bar was connected to a digital monitor to control the partial pressure of fuel and air sequentially during the mixture preparation inside the CVCC. A $20 \mathrm{kHz}$ pressure transducer $\mathrm{P}_{2}$ (JC690 model, $\pm 0.25 \% \mathrm{FS}$ ) having a range of $0-10 \mathrm{MPa}$ was connected to a $100 \mathrm{MHz}$ Oscilloscope to detect the in-chamber pressure rise during the combustion processes.

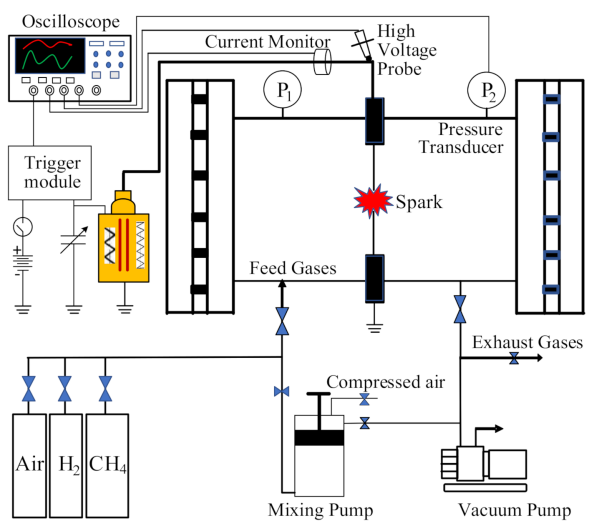

Figure 1. A schematic diagram of the experimental setup.

We first vacuumed the combustion chamber before injecting the appropriate mole fraction of methane, hydrogen, and air to the specific pressure value ( $\left.p_{0}=1 \mathrm{bar}\right)$ using the partial pressure method. The combustible mixture was then mixed by the mixing pump before discharging a spark. A pair of pin-to-pin electrodes having a diameter and spark gap of $2.0 \mathrm{~mm}\left(d_{\text {dia }}=d_{\text {gap }}=2 \mathrm{~mm}\right)$ centrally ignited the premixed mixture by various ignition energies $\left(\mathrm{E}_{\mathrm{ig}}\right)$, where $\mathrm{E}_{\mathrm{ig}}$ can be varied with capacitors. To measure in situ $\mathrm{E}_{\mathrm{ig}}$, an 
ignition circuit was employed by which the positive side was connected to a high-voltage car ignition coil, and the negative side was connected to the ground. $E_{\text {ig }}$ was directly calculated by integration of the product of the discharge current $I(t)$ and the voltage $V(t)$ across the spark gap, where $I(t)$ and $V(t)$ signals obtained by Pearson current monitor 8122 and Pintek high-voltage probe HVP-28HF, respectively, were recorded by a $100 \mathrm{MHz}$ Oscilloscope (Gwinstek GDS-1104B). A typical voltage and current waveform is presented in Figure 2, in which $\mathrm{E}_{\mathrm{ig}} \approx 29 \mathrm{~mJ}$.

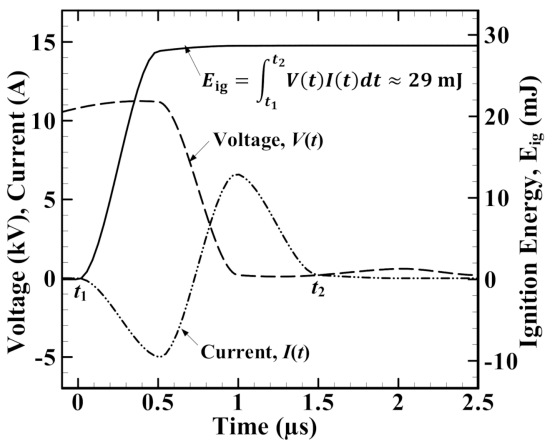

Figure 2. A typical voltage $V(t)$ and current $I(t)$ waveform. Ignition energy $\mathrm{E}_{\mathrm{ig}}=\int_{t 1}^{t 2} V(t) I(t) d t \approx$ $29 \mathrm{~mJ}$, and pulse duration $\left(t_{2}-t_{1}\right) \approx 1.5 \mu \mathrm{s}$.

\subsection{Data Processing and Parameter Definition}

From the evolution of the explosion pressure profile, the laminar burning velocity $\left(S_{u}{ }^{0}\right)$ of the sample mixture was determined using Equation (1) proposed by Matsugi et al. [34]

$$
p=p_{t=t 0}+\int_{t 0}^{t} \frac{3 S_{u}^{0}\left(p_{\mathrm{e}}-p_{0}\right)}{R}\left[1-\frac{p_{e}-p}{p_{\mathrm{e}}-p_{0}}\left(\frac{p_{0}}{p}\right)^{1 / f l}\right]^{2 / 3}\left(\frac{p}{p_{0}}\right)^{c} d t
$$

where $R$ is the inner radius of CVCC, $p_{0}$ is the initial pressure of the mixture, $p$ is the instantaneous pressure in CVCC, $\gamma$ is the specific heat ratio of the unburned mixture, and $p_{\mathrm{e}}$ is the equilibrium pressure under an adiabatic constant volume condition [34], which is determined by using GasEq program.

The laminar burning velocity $S_{u}{ }^{0}$ and the coefficient $c$ were obtained by a leastsquare fit of the observed pressure-time profile to Equation (1), where $c$ represents a pressure-temperature dependence coefficient. $S_{u}{ }^{0}$ was calculated at $10 \%$ to $90 \%$ of the total normalized cumulative heat release (NCHR) to avoid the effects associated to spark ignition and flame-wall interaction, where NCHR was determined based on Equation (3). Each experimental condition was repeated at least five times. Figure 3 reveals in-chamber explosion pressure profiles of $50 \% \mathrm{CH}_{4} / 50 \% \mathrm{H}_{2}$ / air mixtures at $\phi=0.6,0.7$, and 0.8 . All the profiles were readily fitted to Equation (1), as indicated by the bold curves. The laminar burning velocities are $22.7,30.5$, and $39.1 \mathrm{cms}^{-1}$ at equivalence ratios of $0.6,0.7$, and 0.8 , respectively. These values are in close agreement with the previous results by $\mathrm{Hu}$ et al. [19] and Donohoe et al. [20], indicating an accuracy of the pressure profile method applied in this study.

To quantify the time duration for the ignition and combustion phases, we used ignition delay time $\left(t_{\text {delay }}\right)$ and flame rise time $\left(t_{\text {rising }}\right) . t_{\text {delay }}$ is defined as the time duration from the start ignition command to $10 \%$ of the total NCHR, and $t_{\text {rising }}$ is defined as the time duration from $10 \%$ to $90 \%$ of the total NCHR [26] (please see Figure 4), where NCHR is determined from the following equations:

$$
\begin{gathered}
\text { RHRR }=\frac{d p_{\text {in-chamber }}}{d t} \\
\mathrm{NCHR}=\frac{\int_{t_{0}}^{t} \operatorname{RHRR} d t}{\int_{t_{0}}^{t_{\text {end }}} \operatorname{RHRR} d t}
\end{gathered}
$$


where RHRR is the representative heat release rate, $t_{0}$ is the time of discharge, and $t_{\text {end }}$ is the time of peak pressure. The schematic of NCHR calculated from Equation (3) is revealed in Figure 4 , which indicates that the $t_{\text {delay }}$ and $t_{\text {rising }}$ are the shortest at $\phi=0.8$.

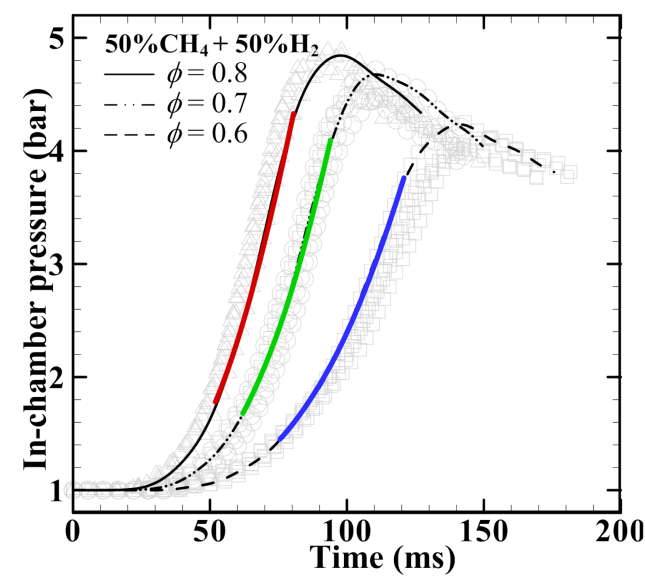

Figure 3. In-chamber pressure profiles (thin curves) and their fitting curves (bold-solid curves).

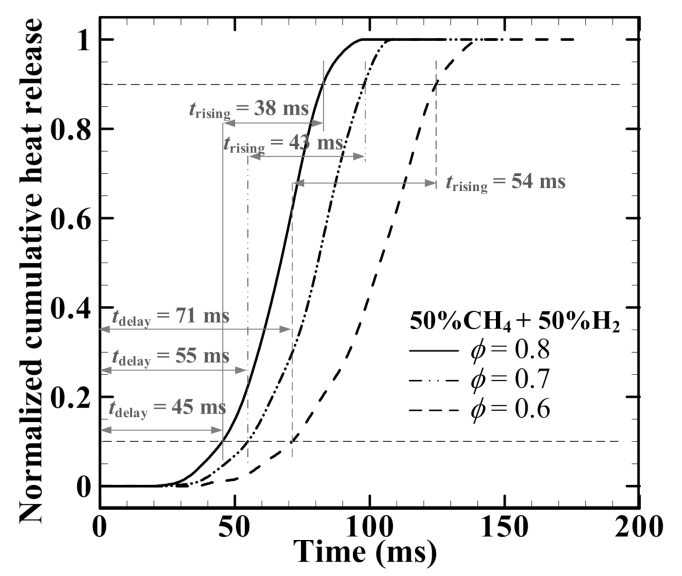

Figure 4. The normalized cumulative heat release (NCHR) for $50 \% \mathrm{CH}_{4} / 50 \% \mathrm{H}_{2} /$ air at different equivalence ratios, $\phi=0.6,0.7$, and 0.8 .

\section{Results and Discussion}

\subsection{In-Chamber Pressure Profile and Laminar Burning Velocity $S_{u}{ }^{0}$}

Figure 5 shows in-chamber pressure profiles during the combustion process of lean methane/hydrogen/air mixtures in different conditions, i.e., three equivalence ratios $\phi=0.6,0.7$, and 0.8 , different hydrogen fractions of $0 \sim 50 \%$ (indicated by $\mathrm{H} 0$ to $\mathrm{H} 5$ ), and various ignition energies $\mathrm{E}_{\mathrm{ig}}=(2.4 \sim 58) \mathrm{mJ}$. Each combustion pressure profile performs a similar behavior, where the pressure first increases rapidly after a period of "constant pressure" to the maximum value ( $\left.p_{\text {peak }}\right)$, and then it declines due to the heat loss through the cold-chamber's wall. The peak pressure value alongside its leftward moving increases when increasing the hydrogen fraction in the mixture and/or equivalence ratio (Figure 5a-c), indicating the boost explosion in a shorter combustion duration. This is because the higher the partial volume of $\mathrm{H}_{2}$ is, the more the amount of $\mathrm{H}, \mathrm{O}$, and $\mathrm{OH}$ radical mole fractions will be released during the combustion, enhancing the chemical reaction [1,22]. Moreover, Figure $5 \mathrm{~d}$ also reveals a slight "leftward moving" of the pressure trace as increasing $\mathrm{E}_{\mathrm{ig}}$ from $2.4 \mathrm{~mJ}$ to $58 \mathrm{~mJ}$, suggesting a shorter combustion duration. The enhanced combustion with increasing $E_{\text {ig }}$ could be attributed to the high concentration of active radicals inside the spark gap [31] and/or high chemical power release [32]. 

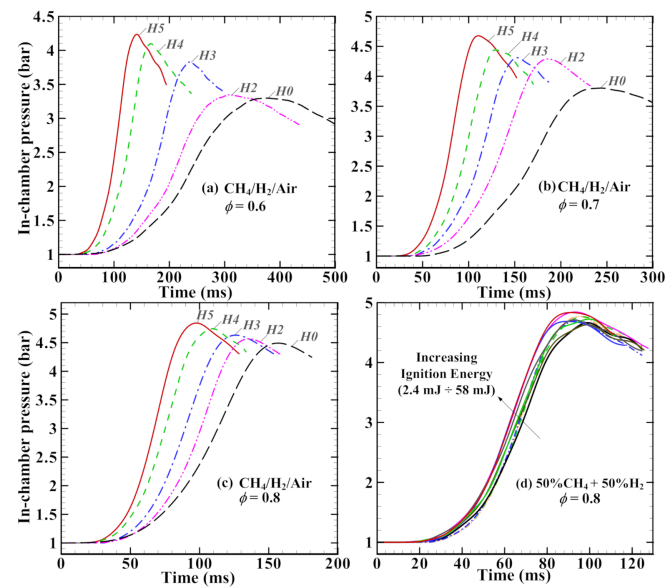

Figure 5. In-chamber pressure profiles for lean $\mathrm{CH}_{4} / \mathrm{H}_{2}$ /air. (a-c) Three equivalence ratios $\phi=0.6$, $0.7,0.8$ with different $\mathrm{H}_{2}$ fractions of $0 \sim 50 \%$ (indicated by $\mathrm{H} 0$ to $\mathrm{H} 5$ ); (d) $50 \% \mathrm{CH}_{4} / 50 \% \mathrm{H}_{2}$ at $\phi=0.8$ by varying the ignition energies $\mathrm{E}_{\mathrm{ig}}=(2.4 \sim 58) \mathrm{mJ}$.

Values of $S_{u}^{0}$ calculated by applying Equation (1) to the pressure profiles (as indicated in Figure 5) are plotted against the hydrogen volume fractions in Figure $6 . S_{u}{ }^{0}$ increases non-linearly with increasing hydrogen volume fraction for all equivalence ratios $(\phi=0.6$, 0.7 , and 0.8 ). The value of $S_{u}{ }^{0}$ gradually increases as the hydrogen faction increases from 0 to $20 \%$ and is rather rapid when the hydrogen fraction is greater than $20 \%$ for three equivalence ratios $(\phi=0.6,0.7$, and 0.8$)$. Adding $20 \%$ of the hydrogen fraction to the mixtures results in less than $10 \%$ of the increasing $S_{u}{ }^{0}$ at $\phi=0.7$ and 0.8 , while it is $35 \%$ for $\phi=0.6$. This is probably because the pure $\mathrm{CH}_{4} /$ air mixture at $\phi=0.6$ is close to the lower flammability limits having very low $S_{u}{ }^{0} \sim 7 \mathrm{~cm} / \mathrm{s}$. To the term of burning velocity, the higher the $\mathrm{H}_{2}$, the more $\mathrm{H}+$ is provided, the more active the chemical reaction becomes, and a higher burning velocity is realized.

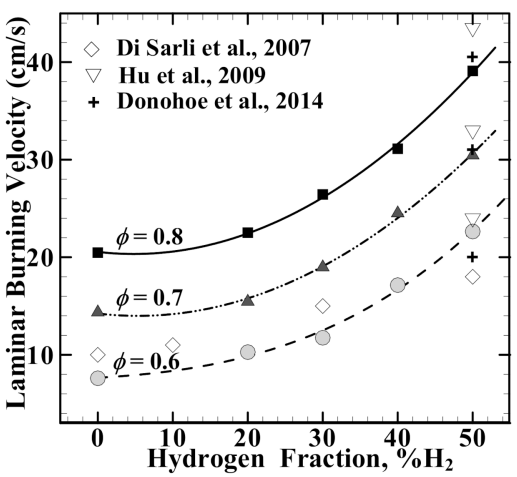

Figure 6. Effect of additional hydrogen on laminar burning velocity of lean $\mathrm{CH}_{4}$ / air mixtures at three equivalence ratios $(\phi=0.6,0.7$, and 0.8$)$. The solid symbols are experimental data, and the curves are their fitting lines.

\subsection{Ignition Delay Time $\left(t_{\text {delay }}\right)$ and Flame Rising Time $\left(t_{\text {rising }}\right)$}

For successful flame development, $t_{\text {delay }}$ offers an effective way to evaluate the physicochemical property of a combustible fuel-air mixture [25,35-37]. $T_{\text {delay }}$ is defined as the time duration from the start ignition command to $10 \%$ of the total normalized cumulative heat release $(\mathrm{NCHR})$ in which $t_{\text {delay }}$ could be affected by $\mathrm{E}_{\mathrm{ig}}$. Figure $7 \mathrm{a}$ indicates that the larger $\mathrm{E}_{\mathrm{ig}}$ is, the shorter the value of $t_{\text {delay }}$ is. For instance, $t_{\text {delay }}$ decreases approximately $15 \%$ when increasing $\mathrm{E}_{\mathrm{ig}}$ from $2.4 \mathrm{~mJ}\left(t_{\text {delay }}=46.5 \mathrm{~ms}\right)$ to $58 \mathrm{~mJ}\left(t_{\text {delay }}=40.5 \mathrm{~ms}\right)$. The values of $t_{\text {delay }}$ are plotted against $\mathrm{E}_{\mathrm{ig}}$ in Figure $7 \mathrm{~b}$, which indicates a transition of $t_{\text {delay }}$ at $\mathrm{E}_{\mathrm{ig}} \sim 24 \mathrm{~mJ}$. In the pre-transition, when $\mathrm{E}_{\mathrm{ig}}$ is increased from $2.4 \mathrm{~mJ}$ to $24 \mathrm{~mJ}$, values of 
$t_{\text {delay }}$ enormously drop from $46.5 \mathrm{~ms}$ to $41.6 \mathrm{~ms}$. However, a very modest decrease in $t_{\text {delay }}$ from $41.6 \mathrm{~ms}$ to $40.5 \mathrm{~ms}$ is observed when $\mathrm{E}_{\mathrm{ig}}>\mathrm{E}_{\mathrm{ig} \text {,critical }} \approx 24 \mathrm{~mJ}$ in the post-transition. The decrease in $t_{\text {delay }}$ with increasing $\mathrm{E}_{\mathrm{ig}}$ could be attributed to the high concentration of active radical species [31] and/or the growth in the chemical reaction rates [32]. However, when $\mathrm{E}_{\mathrm{ig}}>24 \mathrm{~mJ}$, the additional $\mathrm{E}_{\mathrm{ig}}$ has a marginal effect on $t_{\text {delay }}$, possibly due to the saturation of the refreshed recirculation mixture by vortices inside the spark gap induced by the shock wave $[38,39]$ having saturated active radicals. The other possibility is the increase in heat conduction losses to the electrodes with increasing $E_{i g}$ [32]. The existence of $E_{\text {ig,critical }}$ could

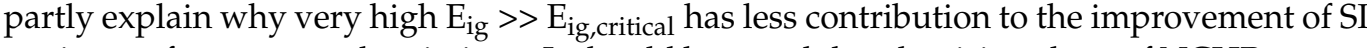
engine performance and emissions. It should be noted that the rising slope of NCHR curves from $10 \%$ to $90 \%$ are quite similar at different $E_{i g}$, suggesting a lesser and/or negligible influence of $\mathrm{E}_{\mathrm{ig}}$ on the flame rising time $\left(t_{\text {rising }}\right)$ and laminar burning velocity.
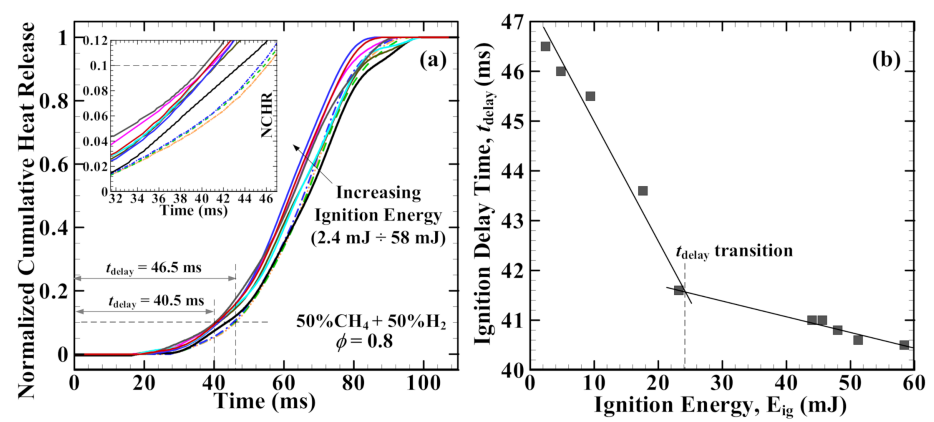

Figure 7. Effect of ignition energy on the ignition delay time $\left(t_{\text {delay }}\right)$ : $(\mathbf{a})$ where $E_{\text {ig }}$ is varied in a range of $2.4 \mathrm{~mJ}-58 \mathrm{~mJ}$ using a car ignition coil. The inset is a close-look at very beginning of NCHR in which $t_{\text {delay }}$ values are determined. (b) The value of $t_{\text {delay }}$ (solid symbols) are plotted against $\mathrm{E}_{\mathrm{ig}}$, showing a $t_{\text {delay }}$ transition at $\mathrm{E}_{\mathrm{ig} \text {, critical }} \approx 24 \mathrm{~mJ}$.

Figure 8 presents the effect of additional $\mathrm{H}_{2}$ volume fraction on $t_{\text {delay }}$ (Figure $8 \mathrm{a}$ ) and $t_{\text {rising }}$ (Figure $8 \mathrm{~b}$ ) of lean $\mathrm{CH}_{4}$ /air mixtures. Each data point in Figure 8 is an average value of at least five ignition trials using $E_{i g}>20 \mathrm{~mJ}$ to minimize the effect of $E_{i g}$ on the early stage of flame propagation (as presented in Figure 7 ). As can be seen, $t_{\text {delay }}$ and $t_{\text {rising }}$ decline in an accelerated tendency with the increase in the hydrogen fraction for the promoted chemical reaction process by more $\mathrm{H}^{+}$, especially when the hydrogen fraction is greater than $20 \%$. The declining slope is much steeper for the leaner mixture. For instance, $t_{\text {delay }}\left(t_{\text {rising }}\right)$ drops $48 \%(70 \%), 44 \%(55 \%)$, and $36 \%$ (33\%) when increasing the $\mathrm{H}_{2}$ volume fraction from 0 to $50 \%$ for lean $\mathrm{CH}_{4}$ / air mixture at an equivalence ratio of $0.6,0.7$, and 0.8 , respectively. Furthermore, the leaner mixture has a larger critical flame initiation radius $[28,29]$ and a lower flame speed (as presented in Figure 6); hence, longer $t_{\text {delay }}$ and $t_{\text {rising }}$ are observed when comparing three equivalence ratios.
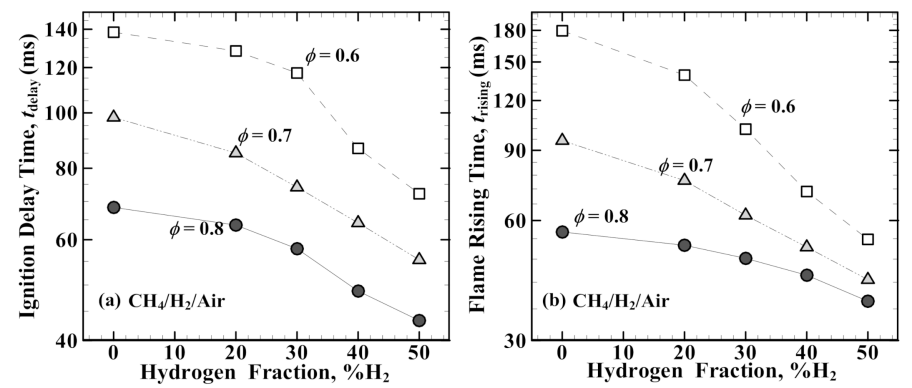

Figure 8. Effect of hydrogen volume fraction on (a) $t_{\text {delay }}$ and (b) $t_{\text {rising }}$ of lean $\mathrm{CH}_{4} /$ air mixtures at three equivalence ratios of $0.6,0.7$, and 0.8 .

For clear observation on the variation of $t_{\text {delay }}$ and $t_{\text {rising }}$ in the combustion process, the occupy ratios of $t_{\text {delay }} /\left(t_{\text {delay }}+t_{\text {rising }}\right)$ and $t_{\text {rising }} /\left(t_{\text {delay }}+t_{\text {rising }}\right)$ are presented in Figure 9 . 
As can be seen, the value of $t_{\text {delay }} /\left(t_{\text {delay }}+t_{\text {rising }}\right)$ rises as $\% \mathrm{H}_{2}$ rises at $\phi=0.6$ and 0.7 , but it slightly decreases at $\phi=0.8$ (please see the top of Figure 9 ). The reverse trend of $t_{\text {rising }} /\left(t_{\text {delay }}+t_{\text {rising }}\right)$ is revealed at the bottom of Figure 9 . This is possibly due to the competition between $t_{\text {delay }}$ and $t_{\text {rising }}$ in the combustion process, by which the dropping slope of $t_{\text {rising }}$ is much steeper than that of $t_{\text {delay }}$ at $\phi=0.6$ and 0.7 , but the reverse is true at $\phi=0.8$.

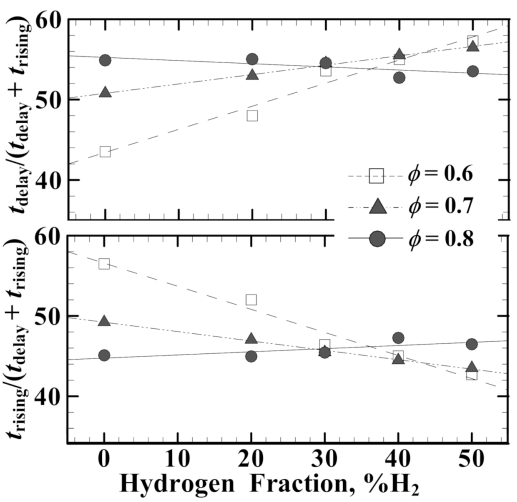

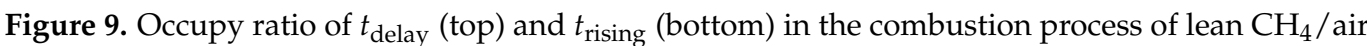
mixtures under different conditions.

\section{Conclusions}

We ignited lean hydrogen-methane-air mixtures at $\phi=0.6,0.7$, and 0.8 with varying hydrogen volume fractions ( $0-50 \%$ ) in a constant volume combustion chamber via a pair of pin-to-pin electrodes at a fixed gap of $2 \mathrm{~mm}$. The effect of ignition energy and additional hydrogen fraction on the in-chamber pressure rise, laminar burning velocity, and explosion duration characteristics (i.e., $t_{\text {delay }}$ and $t_{\text {rising }}$ ) were then investigated. These measurements reveal the following points.

(1) The peak of the in-chamber pressure profile increases when increasing hydrogen volume fraction at three equivalence ratios of $0.6,0.7$, and 0.8 , suggesting a higher heat release.

(2) The leftward moving of peak pressure is observed when increasing hydrogen volume fraction, equivalence ratio, and ignition energy, suggesting a faster flame propagation and/or shorter explosion duration time.

(3) $S_{u}{ }^{0}$ increases non-linearly with increasing hydrogen volume fraction for all equivalence ratios $(\phi=0.6,0.7$, and 0.8$)$. Su0 gradually increases as the hydrogen fraction increases from 0 to $20 \%$ and is rather rapid when the hydrogen fraction is greater than $20 \%$.

(4) There is a $t_{\text {delay }}$ transition at a critical value ignition energy (i.e., $E_{\text {ig,critical }} \sim 24 \mathrm{~mJ}$ for $50 \% \mathrm{CH}_{4} / 50 \% \mathrm{H}_{2}$ /air mixture at $\phi=0.8$ ) in which $t_{\text {delay }}$ drastically drops in the pre-transition and gradually decreases in the post-transition. The existence of $\mathrm{E}_{\mathrm{ig}, \mathrm{critical}}$

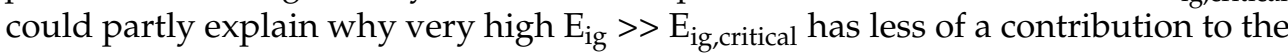
improvement of SI engine performance and emissions.

(5) Both $t_{\text {delay }}$ and $t_{\text {rising }}$ decrease with increasing hydrogen fraction in the lean methane/air mixtures. For the leaner mixtures ( $\phi=0.6$ and 0.7$)$, the dropping slope of $t_{\text {rising }}$ is much steeper than that of $t_{\text {delay, }}$, while the reverse trend is true at $\phi=0.8$.

The results suggest that a small amount of hydrogen fraction (20-30\%) could be applied to the lean-burn natural gas engines. In future work, we will convert the traditional electrical motor used gasoline engine to lean natural-gas-fueled hydrogen. Hence, the primary results should be useful to our further understanding of the ignition timing and explosion characteristics that play an important role in achieving an optimal combustion phase and power output. 


\begin{abstract}
Author Contributions: Conceptualization, M.T.N.; methodology, M.T.N., M.T.P. and P.N.D.; validation, Q.T.P. and V.V.L.; formal analysis, M.T.N. and V.V.L.; investigation, M.T.N. and M.T.P.; resources, M.T.N.; data curation, M.T.N. and P.N.D.; writing-original draft preparation, M.T.N. and Q.T.P.; writing—review and editing, M.T.N. and Q.T.P.; visualization, V.V.L., P.N.D. and M.T.P.; supervision, M.T.N.; project administration, M.T.N. All authors have read and agreed to the published version of the manuscript.
\end{abstract}

Funding: This research was funded by the MINISTRY OF EDUCATION AND TRAINING, VIETNAM, grant number B2021-DNA-02.

Conflicts of Interest: The authors declare no conflict of interest.

\title{
References
}

1. Okafor, E.; Hayakawa, A.; Nagano, Y.; Kitagawa, T. Effects of hydrogen concentration on premixed laminar flames of hydrogenmethane-air. Int. J. Hydrogen Energy 2014, 39, 2409. [CrossRef]

2. Benaissa, S.; Adouane, B.; Ali, S.M.; Mohammad, A. Effect of hydrogen addition on the combustion characteristics of premixed biogas/hydrogen-air mixtures. Int. J. Hydrogen Energy 2021, 46, 18661-18677. [CrossRef]

3. Bae, C.; Kim, J. Alternative fuels for internal combustion engines. Proc. Combust. Inst. 2017, 36, 3389-3413. [CrossRef]

4. $\quad$ El-Kassaby, M.M.; Eldrainy, Y.A.; Khidr, M.E.; Khidr, K.I. Effect of hydroxy (hho) gas addition on gasoline engine performance and emissions. Alex. Eng. J. 2016, 55, 243-251. [CrossRef]

5. Nakata, K.; Nogawa, S.; Takahashi, D.; Yoshihara, Y.; Kumagai, A.; Suzuki, T. Engine technologies for achieving $45 \%$ thermal efficiency of s.I. Engine. SAE Int. J. Engines 2015, 9, 179-192. [CrossRef]

6. Rapp, V.H.; DeFilippo, A.; Saxena, S.; Chen, J.-Y.; Dibble, R.W.; Nishiyama, A.; Moon, A.; Ikeda, Y. Extending lean operating limit and reducing emissions of methane spark-ignited engines using a microwave-assisted spark plug. J. Combust. 2012, 2012, 8. [CrossRef]

7. Hayashi, N.; Sugiura, A.; Abe, Y.; Suzuki, K. Development of ignition technology for dilute combustion engines. SAE Int. J. Engines 2017, 10, 984-995. [CrossRef]

8. Tsuboi, S.; Miyokawa, S.; Matsuda, M.; Yokomori, T.; Iida, N. Influence of spark discharge characteristics on ignition and combustion process and the lean operation limit in a spark ignition engine. Appl. Energy 2019, 250, 617-632. [CrossRef]

9. Aleiferis, P.G.; Taylor, A.M.K.P.; Ishii, K.; Urata, Y. The nature of early flame development in a lean-burn stratified-charge spark-ignition engine. Combust. Flame 2004, 136, 283-302. [CrossRef]

10. Yu, S.; Zheng, M. Future gasoline engine ignition: A review on advanced concepts. Int. J. Engine Res. 2020, $22,1743-1775$. [CrossRef]

11. Ma, F.; Wang, Y.; Liu, H.; Li, Y.; Wang, J.; Zhao, S. Experimental study on thermal efficiency and emission characteristics of a lean burn hydrogen enriched natural gas engine. Int. J. Hydrogen Energy 2007, 32, 5067-5075. [CrossRef]

12. Ma, F.; Wang, Y. Study on the extension of lean operation limit through hydrogen enrichment in a natural gas spark-ignition engine. Int. J. Hydrogen Energy 2008, 33, 1416-1424. [CrossRef]

13. Wang, X.; Zhang, H.G.; Lei, Y.; Bai, X.L.; Sun, X.N.; Wang, D.J.; Yao, B.F. Effects of engine operating parameters on lean combustion limit of hydrogen enhanced natural gas engine. Adv. Mater. Res. 2011, 383-390, 6116-6121. [CrossRef]

14. Karim, G.A.; Wierzba, I.; Al-Alousi, Y. Methane-hydrogen mixtures as fuels. Int. J. Hydrogen Energy 1996, 21, 625-631. [CrossRef]

15. Akansu, S.; Kahraman, N.; Ceper, B. Experimental study on a spark ignition engine fuelled by methane-hydrogen mixtures. Int. J. Hydrogen Energ 2007, 32, 4279-4284. [CrossRef]

16. Ilbas, M.; Crayford, A.; Yilmaz, I.; Bowen, P.; Syred, N. Laminar-burning velocities of hydrogen-air and hydrogen-methane-air mixtures: An experimental study. Int. J. Hydrogen Energy 2006, 31, 1768-1779. [CrossRef]

17. Chen, Z. Effects of hydrogen addition on the propagation of spherical methane/air flames: A computational study. Int. J. Hydrogen Energy 2009, 34, 6558-6567. [CrossRef]

18. Di Sarli, V.; Benedetto, A.D. Laminar burning velocity of hydrogen-methane/air premixed flames. Int. J. Hydrogen Energy 2007, 32, 637-646. [CrossRef]

19. Hu, E.; Huang, Z.; He, J.; Jin, C.; Zheng, J. Experimental and numerical study on laminar burning characteristics of premixed methane-hydrogen-air flames. Int. J. Hydrogen Energy 2009, 34, 4876-4888. [CrossRef]

20. Donohoe, N.; Heufer, A.; Metcalfe, W.K.; Curran, H.J.; Davis, M.L.; Mathieu, O.; Plichta, D.; Morones, A.; Petersen, E.L.; Güthe, F. Ignition delay times, laminar flame speeds, and mechanism validation for natural gas/hydrogen blends at elevated pressures. Combust. Flame 2014, 161, 1432-1443. [CrossRef]

21. Di Sarli, V.; Di Benedetto, A.; Long, E.J.; Hargrave, G.K. Time-resolved particle image velocimetry of dynamic interactions between hydrogen-enriched methane/air premixed flames and toroidal vortex structures. Int. J. Hydrogen Energy 2012, 37, 16201-16213. [CrossRef]

22. Sun, Z.-Y. Turbulent explosion characteristics of stoichiometric syngas. Int. J. Energy Res. 2018, 42, 1225-1236. [CrossRef]

23. Salzano, E.; Cammarota, F.; Di Benedetto, A.; Di Sarli, V. Explosion behavior of hydrogen-methane/air mixtures. J. Loss Prevent. Process Ind. 2012, 25, 443-447. [CrossRef] 
24. Wang, J.; Huang, Z.; Fang, Y.; Liu, B.; Zeng, K.; Miao, H.; Jiang, D. Combustion behaviors of a direct-injection engine operating on various fractions of natural gas-hydrogen blends. Int. J. Hydrogen Energy 2007, 32, 3555-3564. [CrossRef]

25. Petrukhin, N.V.; Grishin, N.N.; Sergeev, S.M. Ignition delay time-An important fuel property. Chem. Technol. Fuels Oils 2016, 51, 581-584. [CrossRef]

26. Hwang, J.; Bae, C.; Park, J.; Choe, W.; Cha, J.; Woo, S. Microwave-assisted plasma ignition in a constant volume combustion chamber. Combust. Flame 2016, 167, 86-96. [CrossRef]

27. Jung, D.; Sasaki, K.; Iida, N. Effects of increased spark discharge energy and enhanced in-cylinder turbulence level on lean limits and cycle-to-cycle variations of combustion for si engine operation. Appl. Energy 2017, 205, 1467-1477. [CrossRef]

28. Kelley, A.P.; Jomaas, G.; Law, C.K. Critical radius for sustained propagation of spark-ignited spherical flames. Combust. Flame 2009, 156, 1006-1013. [CrossRef]

29. Chen, Z.; Burke, M.P.; Ju, Y. Effects of lewis number and ignition energy on the determination of laminar flame speed using propagating spherical flames. Proc. Combust. Inst. 2009, 32, 1253-1260. [CrossRef]

30. Chen, Z.; Burke, M.P.; Ju, Y. On the critical flame radius and minimum ignition energy for spherical flame initiation. Proc. Combust. Inst. 2011, 33, 1219-1226. [CrossRef]

31. Han, J.; Yamashita, H.; Hayashi, N. Numerical study on the spark ignition characteristics of a methane-air mixture using detailed chemical kinetics: Effect of equivalence ratio, electrode gap distance, and electrode radius on mie, quenching distance, and ignition delay. Combust. Flame 2010, 157, 1414-1421. [CrossRef]

32. Kravchik, T.; Sher, E.; Heywood, J.B. From spark ignition to flame initiation. Combust. Sci. Technol. 1995, 108, 1-30. [CrossRef]

33. Zhou, M.; Li, G.; Liang, J.; Ding, H.; Zhang, Z. Effect of ignition energy on the uncertainty in the determination of laminar flame speed using outwardly propagating spherical flames. Proc. Combust. Inst. 2019, 37, 1615-1622. [CrossRef]

34. Matsugi, A.; Shiina, H.; Takahashi, A.; Tsuchiya, K.; Miyoshi, A. Burning velocities and kinetics of h2/nf3/n2, ch4/nf3/n2, and $\mathrm{c} 3 \mathrm{~h} 8 / \mathrm{nf3} / \mathrm{n} 2$ flames. Combust. Flame 2014, 161, 1425-1431. [CrossRef]

35. Chen, R.; Okazumi, R.; Nishida, K.; Ogata, Y. Effect of ethanol ratio on ignition and combustion of ethanol-gasoline blend spray in disi engine-like condition. SAE Int. J. Fuels Lubr. 2015, 8, 264-276. [CrossRef]

36. Saito, N.; Minamoto, Y.; Yenerdag, B.; Shimura, M.; Tanahashi, M. Effects of turbulence on ignition of methane-air and n-heptaneair fully premixed mixtures. Combust. Sci. Technol. 2017, 190, 452-470. [CrossRef]

37. Bradley, D.; Lung, F.K.K. Spark ignition and the early stages of turbulent flame propagation. Combust. Flame 1987, 69, 71-93. [CrossRef]

38. Castela, M.; Stepanyan, S.; Fiorina, B.; Coussement, A.; Gicquel, O.; Darabiha, N.; Laux, C.O. A 3-d dns and experimental study of the effect of the recirculating flow pattern inside a reactive kernel produced by nanosecond plasma discharges in a methane-air mixture. Proc. Combust. Inst. 2017, 36, 4095-4103. [CrossRef]

39. Bane, S.P.M.; Ziegler, J.L.; Shepherd, J.E. Investigation of the effect of electrode geometry on spark ignition. Combust. Flame 2015, 162, 462-469. [CrossRef] 